\title{
ENHANCING GRADUATE EMPLOYABILITY BEYOND CREATIVE DESIGN DEGREE PROGRAMMES
}

\author{
Christian McLENING, Franziska CONRAD and Alison ZORRAQUIN \\ Arts University Bournemouth, United Kingdom
}

\begin{abstract}
Against the backdrop of the 2017 Design Council: Design a Future Economy, developing skills for productivity and innovation [1] the paper builds on a number of existing studies that examine the mix of design graduate skills and attributes beyond the core design programme curriculum. A pilot study event held in 2019 aimed to explore potential opportunities to develop graduates beyond their core course, seeking to enhance design graduate employability. The paper explores the impact of that pilot study and outlines future developments.
\end{abstract}

A pilot study event was conducted in 2019 by a UK higher education-based institution that developed a range of voluntary courses and workshops for recent graduates that were in addition to the core degree programmes. The initiative was presented as a creative 'Graduate Advantage' initiative and held over a number of weeks at the university with external speakers, workshops, talks and classes that recent graduates could engage with via a self-selective sign up system. Graduate participants were from a broad range of creative design-based subjects, which included: Fashion Design, Modelmaking and Architecture, the majority having finished their formal degree programme only a few weeks earlier.

The individual courses and workshops selected by the participants during the pilot study event have then been evaluated against three subcategories developed by Hernandez et al [2]. The subcategories are grouped into: (1) Knowledge and understanding, (2) Technical capabilities and methods, and (3) Attributes and capabilities. The subcategories can then be compared to the student engagement patterns when selecting the various events within the creative 'Graduate Advantage' initiative and considered against the student qualitative feedback on completion of the activities.

The analysis of the categories, the engagement behaviour and the qualitative feedback can be used to draw conclusions about the impact of the event which will then inform recommendations for the next series of workshops and classes. Incrementally building examples of best practice in enhancing creative design student's employability profile. The wider context of the study will be considered against current literature including the report by The Design Economy: 2018 the state of design in the UK [3], and example of other graduate skills and graduate attribute studies.

The results and analysis of the initial 2019 pilot study will be presented in the paper along with examples and recommendations of best practice for developing creative design graduate employability skills and attributes.

The results of the second 'Graduate Advantage' initiative to be held in 2020 will be presented at the EPDE conference 2020.

Keywords: Employability, graduate attributes

\section{INTRODUCTION}

As the design profession develops to meet the ever-evolving global demands so do those who work with designers during their training. Design education in higher education revolves around a curriculum to help students learn, practice and develop their own design profile. This study seeks to explore and develop a 'Graduate Advantage' initiative to give recent design graduates additional opportunities to build upon their core design education, helping to build a stronger more employable design profile. The opportunity comes within a window of time at the end of formal degree studies and ahead of the public design shows and exhibitions that often follow design programmes. This initiative offers recent graduates the opportunity to build upon their core education with voluntary and self-selected activities. The "Graduate Advantage' initiative piloted in 2019 offered a mixture of external speakers, workshops, talks and classes to graduates wanting to enhance their design skills and attributes beyond the core design 
degree programme. For reference within this paper creative Skills and Attributes are to be considered as:

- Skills are considered as a tangible ability on a specific task or activity.

- Attributes are a little more intangible, represented as a characteristic or quality of approach and aptitude.

\section{LITERATURE REVIEW}

Skills development is a key focus of the UK Government. It is one of ten key pillars in its Industrial Strategy and recognition that skills development is as important to growth as infrastructure, investment and trade [5].

Students require skills and attributes that reach beyond the scope of their degree programmes to secure employment during their studies and post-graduation. Understanding and acknowledging the difference between attributes and skills by offering an appropriate mix of supporting development events is crucial in the process of design student's holistic education.

The types of skills identified for future employability by the World Economic Forum 2018 [4]. are: complex problem solving, critical thinking, creativity, people management and coordinating with others listed in their top 5 skills for employment in 2020 which highlights a clear shift over skills listed in 2015 (figure 1) [4].

\begin{tabular}{cl} 
in & $\mathbf{2 0 2 0}$ \\
\hline 1. & Complex Problem Solving \\
2. & Critical Thinking \\
3. & Creativity \\
4. & People Management \\
5. & Coordinating with Others \\
6. & Emotional Intelligence \\
7. Judgment and Decision Making \\
8. & Service Orientation \\
9. & Negotiation \\
10. & Cognitive Flexibility
\end{tabular}

\begin{tabular}{ll} 
in & $\mathbf{2 0 1 5}$ \\
\hline 1. & Complex Problem Solving \\
2. & Coordinating with Others \\
3. & People Management \\
4. & Critical Thinking \\
5. & Negotiation \\
6. & Quality Control \\
7. & Service Orientation \\
8. Judgment and Decision Making \\
9. & Active Listening \\
10. & Creativity
\end{tabular}

Figure 1. Top 10 Skills for the fourth industrial revolution [6]

The top 5 match skills developed when studying the arts, humanities and social sciences and can be divided under three broad headings: communication and collaboration; research and analysis and attitudes and behaviours characterised by independence and adaptability. Design students' skills open a wide range of employment options across the private, public and third sectors [7].

It is evident that design graduates are able to move between careers over their working life, using their generic skills to adapt to different industries and become successful leaders and managers as well as successfully contributing and running creative business over the course of their design careers [7].

The future economy requires a high level of skills and advance knowledge that most of the UK workforce does not currently have [3]. Design graduates are expected to be able to span sectors and occupations and could therefore be in high demand in the future. To ensure that all graduates are equipped with the right set of skills for a changing economy the Design Council recommends incorporating design methods, tools and approaches alongside art into STEM subjects [3]. The Design Council also recommends for higher education institutions to introduce more flexible boundaries in the delivery of discipline specific knowledge. More multi-disciplinary education is required to prepare young design graduates for a future in employment [3].

When talking of attributes, we go beyond subject specific skills and knowledge. Employers highlight their desire for the following attributes in graduate designers: creativity - openness to feedback - a passion to learn - an ability to work across disciplines - empathy - problem solving. Creativity and empathy were highlighted as most valuable [8]. This aligns well with the findings above. Employability studies demonstrate the positive impact of team projects and highlight the value to graduates as they progress into their design and engineering career [9]. External competitions and the value of peer and public testing are also emphasized as valuable tools in the development of graduate skills and attributes that reach beyond subject knowledge [9]. 
A balanced mix of extracurricular skills and attributes in graduating design students is essential in enhancing their levels of employability during their studies and after graduation. Creative universities in the UK are therefore developing frameworks and mind-sets embedded in curricular as well as extracurricular activities. Hernandez et al. [2] divide graduate attributes into the following three categories: (1) Knowledge and understanding, (2) Technical capabilities and methods, and (3) Attributes and capabilities; which allow student to access knowledge and skills that can help them develop employability attributes. In section 2 the results of the pilot study at Arts University Bournemouth have been analysed in line with these three attribute categories.

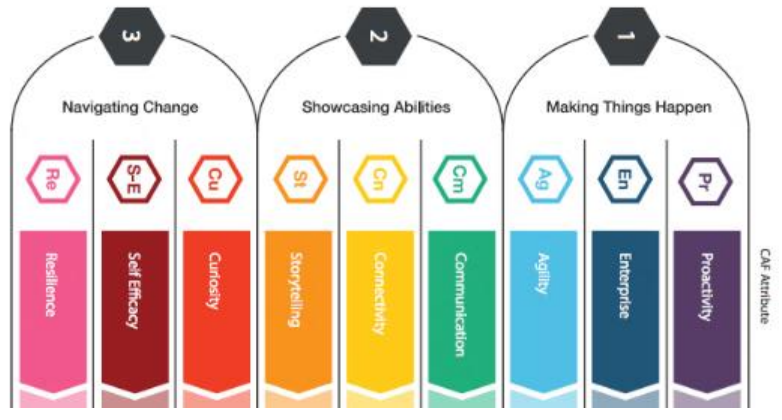

Figure 2. UAL Creative Attributes Framework [10]

Another valuable way of categorising creative attributes can be found in the UAL (University of the Arts London) creative attributes framework (figure 2) which also applies a 3-level approach. The focus here is on 1: creative outputs, 2: the student's ability to communicate those outputs, and 3: the impact these outputs can have on the students as well as on the community [10]. Part of the framework is a repository of case studies outlining graduate success and giving advice to current design students with regards to running their own businesses or survival in the creative industry. It includes gaining real-life experience through interning, to attend all talks and events offered by the university, to find an industry mentor to run ideas by and very practical advice such as finding part-time work in an area of interest or related to the business students are aspiring to start [11].

\section{METHODOLOGY}

The initial 'graduate advantage' pilot study initiative was proposed and developed with the aim of enhancing design graduate employability. Recent graduates were offered the opportunity to engage with several external speakers, workshops, talks and classes. The events were held after the final formal design programmes ended and before most programmes held public exhibitions and graduate shows. Using the lens of Hernandez et al [2] we can examine the clusters of each type of activity:

- Knowledge and Understanding: The focus for graduates here was on building additional understanding of how to do things that were beyond their core degree programme. Such as new insights into aspects of the design profession. Often delivering tangible information.

- Technical Capabilities and Methods: very tangible and practical, such as a short computer software or first aid course certificate. These were adding extra aspects to a graduate profile.

- Attributes and Capabilities: A stronger focus on developing the aptitude and attitude that could unlock the potential of a new graduate designer. More intangible aspects of building confidence, considering the wider context and personal approaches.

The 'Graduate Advantage' pilot study initiative was offered to all graduating art, design and media graduates to develop; self-awareness, opportunity awareness, decision making and transition leaning. As a free voluntary initiative, attendance and feedback was gathered to gauge the perceived value to the graduates. Review of the pilot study will then inform the content of the following iteration of the subsequent 'Graduate Advantage' programme for 2020, which in turn will follow a similar feedback and review process of improvement.

\section{PILOT STUDY (2019)}

The initial 'Graduate Advantage' initiative was conducted as a pilot study in 2019. Attendance figures and qualitative feedback were gathered. A combination of Employability \& Enterprise Skills Week (EESW) in March 2019 open to all students on campus and a series of events under the banner AUB 
Advantage in May 2019 aimed particularly at final year and post graduate students formed the pilot. Graduating final year students across all BA courses and MA students were invited to attend a programme of events that would allow them to build employability attributes beyond the skills and knowledge gained during their degree courses.

\subsection{Analysis of pilot study}

The data collected as a result of the 'Graduate Advantage' pilot study was analysed by grouping them into grouped into: (1) Knowledge and understanding, (2) Technical capabilities and methods, and (3) Attributes and capabilities [2].

The programme offered a variety of external speakers, workshops, talks and classes, some certified such as an online Adobe skills course, first aid, start-up and financial advice, confidence and personality support, alternative careers and introductions to teaching and other creative careers. Attendance of the EESW event in March was significantly higher with 450 attendees than during the AUB Advantage week in May, where 100 of the 235 attendees were registered on the Adobe online course. Whilst the March events were offered to all students on campus the May pilot was aimed only at final year and post-graduate students and fell between final hand-ins and graduation. This is a period during which the final year students were fully committed to the end of year shows and seemed to prioritise their show commitments.

Looking at the data collected for both AUB Advantage events and mapping it against Hernandez et al. graduate attributes as well as reviewing the overall attendance figures several issues become apparent. There is a clear imbalance in the ratio of courses offered with 13 separate events categorised under the attribute of (1) Knowledge and understanding and far fewer covering (2) Technical capabilities and methods, and (3) Attributes and capabilities (figure 3). Based on these findings when planning future events, a better balance could be found by applying graduate attribute mapping systems such as Hernandez' or UALs Creative Attributes Framework (figure 2) to ensure a more even spread. Furthermore, the analysis of attendance could lead to a more focussed extra-curricular programme and the potential embedding of some of the least attended but valuable courses such as mock-interviews and confidence building into the course curriculum.

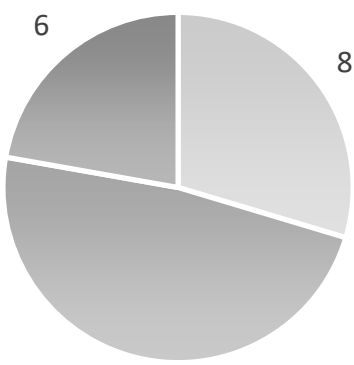

13
- Technical Capabilities \& Methods

- Knowledge \& Understanding

- Attributes \& Capabilities

Figure 3. AUB pilot study programme overview categorised using Hernandez et al. attributes

Separating events by high and low level attendance highlights that 4 out of 6 events categorised as (3) Attributes and capabilities fall amongst those of the sessions with less than 15 students attending (figure 4), whereas all events with 35+ attendees can be categorised as either; (2) Technical Capabilities and methods, or (1) Knowledge and understanding, (figure 5). 


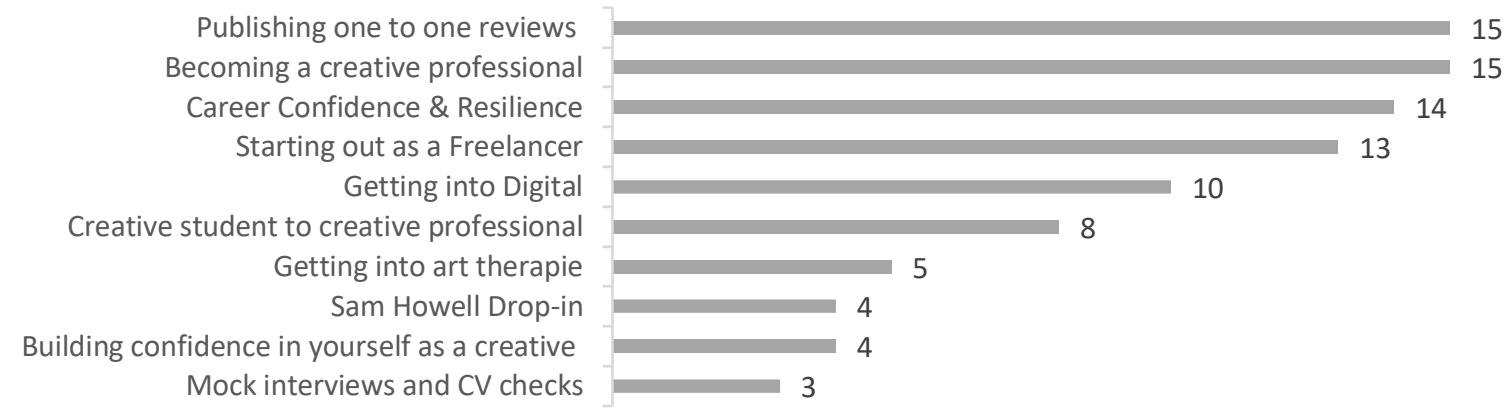

Figure 4. AUB pilot study events with fewer than 15 attendees

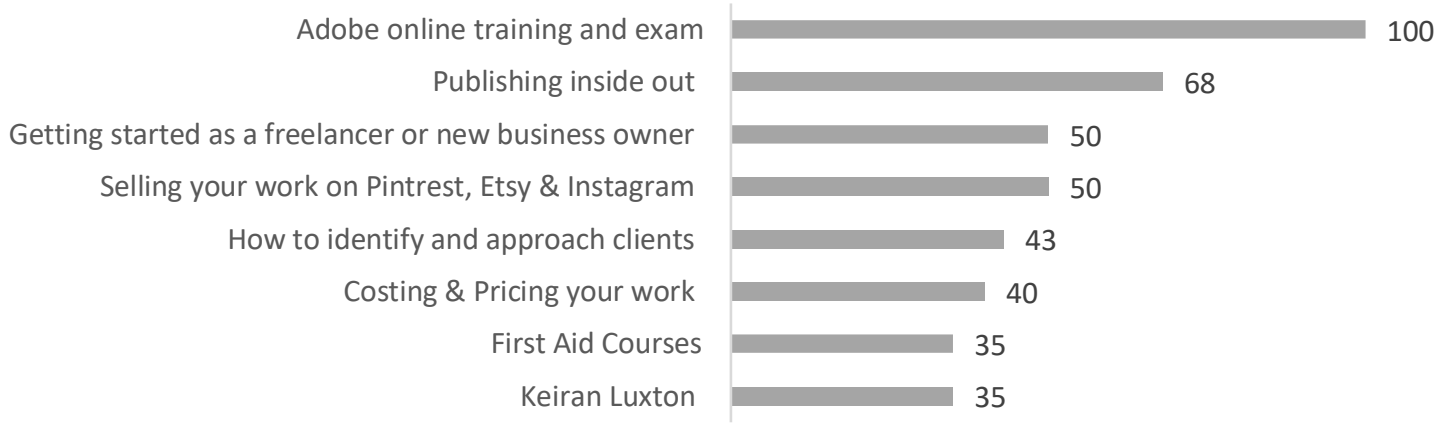

Figure 5. AUB pilot study events with more than 35 attendees

\subsection{Pilot study conclusions}

From the initial 'Graduate Advantage' pilot study 2019 the types of activities that graduates self-selected and valued can be considered. The mix of different options was considered very important to the graduates involved with the pilot study, this allowed them to select what aspect of their own profile they wished to enhance. Student feedback was positive across the board and included comments such as: 'One vital part of this session for me was showing me the possibilities and clarifying values. I built up confidence and belief in myself and learned how to plan a better future career plan' (Becoming a creative professional workshop). By using Hernandez et al [2] and with consideration of the UAL Creative Attributes Framework [10] the mixture of options can provide a richer choice for graduates, while helping to frame the development of the programme content in future years. The 2019 pilot study shows that the Technical Capabilities and Methods were most attended, in the form of a training course with exam. A very tangible activity that students could appreciate. The Knowledge and Understanding activities, such as the 'how to' sessions were also very popular and clearly connected with the graduates. The lowest take up overall was the Attributes and Capabilities aspects, which focused more on the softer more abstract skills, which students did not perceive as so valuable to their profile.

\section{GRADUATE ADVANTAGE: 2020 AND BEYOND}

Before the end of the 2019/20 academic year several extra-curricular events will be held to support student's employability profiles. Aligned with the creative skills framework and skills attributes coined by Hernandez et al [2] the events are looking at boosting students' technical capabilities and methods, their knowledge and understanding as well as their personal attributes and capabilities.

The successful elements of the 2019 programme are being re-run for all students on campus for the 2020 employability week programme, offering activities including; a jobs fair to bookable sessions on starting up creative businesses, financing a business, pitching, portfolio support, networking and how to move into creative career paths outside of the creative industry. 
The 2020 'Graduate Advantage' programme is geared around employability, team working, crossing disciplines and workplace wellbeing. Courses cover personal attribute development such as; confidence building, interview skills and networking (on and offline), creative business knowledge such as funding, some portfolio guidance and skills courses such as last year's certified Adobe course as well as physical and mental health first aid courses. A new addition to the 2020 programme is a 2-day symposium on Design \& Business which includes a company sponsored design jam, open to all students on campus not just final years.

Plans for 2020/21 include expanding the scope of the symposium on Design \& Business by adding a selection of multi-disciplinary workshops in collaboration with businesses and other universities along the south coast. These offers could include collaborative events around; discipline specific language, emotional intelligence, sustainability, creative activism and politics with a real focus on creative problem solving. Partners would join from a variety of disciplines such as Engineering, Social Sciences, Applied Sciences, Robotics, Biomedical, Manufacturing and Charitable foundations and NGOs.

\section{REFERENCES}

[1] Design Council. Design a Future Economy, developing skills for productivity and innovation, Available: https://www.designcouncil.org.uk/resources/report/designing-future-economy-report [Accessed: 21 February 2020] (2017)

[2] Hernandez, R. J. et al.The Value of Design in Innovation: results from a survey within the UK Industry', The Design Journal. Routledge, 20(sup1), 2017, pp. S691-S704. doi: 10.1080/14606925.2017.1353015.

[3] Benton, S., Miller, S. and Reid, S. The Design Economy 2018. 2018, Available: https://www.designcouncil.org.uk/resources/report/design-economy-2018. [Accessed: 21 February 2020] (2018)

[4] World Economic Forum. The Future of Jobs Report 2018, Insight Report - Centre for the New Ecoomy and Society, Available https://www.weforum.org/reports/the-future-of-jobs-report2018 [Accessed: 28 February 2020] (2018), doi: 10.1177/0891242417690604.

[5] HM Government. Industrial strategy - Building a Britain fit for the future, Available: https://www.gov.uk/government/publications/industrial-strategy-building-a-britain-fitfor-the-future [Accessed: 03 March 2020] (2017), doi: 10.1108/01443589410070806.

[6] Gray, A. The 10 skills you need to thrive in the Fourth Industrial Revolution | World Economic Forum, 2016, Available at: https://www.weforum.org/agenda/2016/01/the-10-skills-you-need-tothrive-in-the-fourth-industrial-revolution/ [Accessed: 21 February 2020] (2016).

[7] British Academy for the humanities and social sciences. The right skills : celebrating skills in the arts, humanities and social sciences. British Academy staff, 2017, Available: https://www.thebritishacademy.ac.uk/publications/right-skills-celebrating-skills-artshumanities-and-social-sciences-ahss [Accessed: 03 March 2020] (2017)

[8] Raven, D. et al. What makes a resilient designer?. 2013, doi: 10.1038/news.2011.244.

[9] McLening, C. and Burgess, J. Engineering and design student projects - The impact of team based final major projects on graduate employability. Proceedings of the 20th International Conference on Engineering and Product Design Education, E and PDE 2018, (September), 2018, pp. 1-6.

[10] UAL. UAL: Creative Attributes Framework - guidance for course teams. Available: https://www.arts.ac.uk/about-ual/teaching-and-learning-exchange/careers-andemployability/creative-attributes-framework [Accessed: 03 March 2020] (2016)

[11] UAL. Building a design business (graduate case study)| UAL. 2016, Available at: https://www.arts.ac.uk/about-ual/teaching-and-learning-exchange/careers-andemployability/creative-attributes-framework/making-things-happen/building-a-design-businessgraduate-case-study [Accessed: 11 February 2020] (2016) 